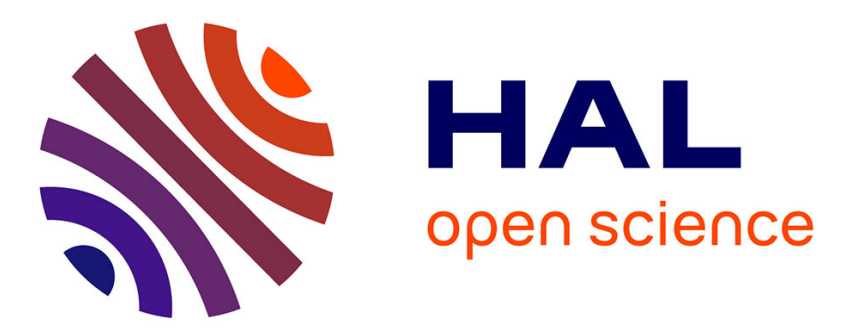

\title{
Towards smart assessment: A metamodel proposal
}

\author{
Marcelo Romero, Wided Guédria, Hervé Panetto, Béatrix Barafort
}

\section{To cite this version:}

Marcelo Romero, Wided Guédria, Hervé Panetto, Béatrix Barafort. Towards smart assessment: A metamodel proposal. 14th OTM/IFAC/IFIP International Workshop on Enterprise Integration, Interoperability and Networking, EI2N 2019, Oct 2019, Kallithea, Rhodes, Greece. pp.12-22, 10.1007/9783-030-40907-4_3. hal-02329055

\section{HAL Id: hal-02329055 https://hal.science/hal-02329055}

Submitted on 23 Oct 2019

HAL is a multi-disciplinary open access archive for the deposit and dissemination of scientific research documents, whether they are published or not. The documents may come from teaching and research institutions in France or abroad, or from public or private research centers.
L'archive ouverte pluridisciplinaire $\mathbf{H A L}$, est destinée au dépôt et à la diffusion de documents scientifiques de niveau recherche, publiés ou non, émanant des établissements d'enseignement et de recherche français ou étrangers, des laboratoires publics ou privés. 


\title{
Towards Smart Assessment: A Metamodel Proposal
}

\author{
Marcelo Romero $^{1,2}$, Wided Guédria ${ }^{1,2}$, Hervé Panetto ${ }^{2}$, and Béatrix Barafort ${ }^{1}$ \\ 1 Luxembourg Institute of Science and Technologie (LIST), 5, Avenue des \\ Hauts-Fourneaux, L-4362, Esch-sur-Alzette, Luxembourg \\ \{marcelo.romero, wided.guedria, beatrix.barafort\}@list.lu \\ 2 Université de Lorraine, Centre National de la Recherche Scientifique (CNRS), \\ Centre de Recherche en Automatique de Nancy (CRAN), Nancy, France \\ herve.panetto@univ-lorraine.fr
}

\begin{abstract}
Assessment initiatives in organisations are focused on the evaluation of organisational aspects aiming to obtain a critic view of their status. The assessment results are used to lead improvement programs or to serve as base for comparative purposes. Assessment approaches may comprise complex tasks demanding a large amount of time and resources. Moreover, assessment results are highly dependent on the assessment input, which may have a dynamic nature due to the constant evolution of organisations. The assessment results should be adaptable to these changes without much effort whilst being able to provide efficient and reliable results. Therefore, providing smart capabilities to the assessment process or to systems in charge of performing assessments represents a step forward in the search for more efficient appraisal processes. This work proposes a metamodel defining the elements of a Smart Assessment, which is guided by elements related to the smartness concept such as knowledge, learning, reasoning and inferring capabilities. The metamodel is further specialized considering a Business Process Interoperability Smart Assessment scenario.
\end{abstract}

Keywords: Process Assessment - Interoperability Assessment · Smartness · Smart Assessment · Metamodel

\section{Introduction}

An assessment is the act of estimating or deciding the amount, value, quality, or importance of a specific entity. In the organisational context, enterprises and the scientific community have pursued to evaluate different aspects such as process performance [1], business processes maturity [2], enterprise interoperability [3], software agility [4], Industry 4.0 readiness [5], enterprise risk management [6], cooperative enterprise information systems interoperability [7], among others. Assessments may serve organisations for descriptive, prescriptive or comparative purposes. The first is based on providing only a current state view of the assessed entity in order to provide an objective vision of the assessed entity to the decision-makers, the second also provides improvement recommendations, and 
the last one allows to perform bench-marking between industries or regions [8]. Performing assessments could imply the consumption of time and resources, making it expensive for organisations, specially when maturity assessment is performed [9]. Moreover, assessment methods may comprise the performing of highly complex and specialized tasks that must be carried by competent assessors, often relying on the manual gathering of evidence to be used to perform the assessment [10,11], which can lead to errors [12]. On the other hand, since the assessment result is highly dependent on its input, changes in the latter may have direct impact on the former, making necessary to re-carry out some of the assessment activities when there is a change in the input to provide a new result.

The improvement of the assessment process is an open research subject that is addressed in both the scientific community and the industry. Several initiatives from different domains such as business process [13], software engineering process $[11,14]$, enterprise interoperability [15], or organisational agility [16] have been proposed throughout the years in the search for assessment approaches with their activities improved through automation methods so as to provide trustworthy, relevant and adaptable results, and to reduce the time and effort of carrying out the assessment. Due to this tendency towards automation, providing smart capabilities to the assessment process may represent a step closer towards the achievement of more efficient appraisals. Smartness is a concept that has different assumptions depending on the domain that it is treated in. However, common points that are domain-independent include capabilities such as sensing, actuating, learning, and knowledge.

This paper presents an initial formalization of a Smart Assessment process introducing a metamodel for describing its elements and their relationships. We aim at answering the research question: "Which are the elements of an assessment process with smart capabilities?". We also present an specialization of the metamodel presenting a metamodel for Business Process Interoperability Smart Assessment. We rely on the use of a metamodel to explain our view of a smart assessment since metamodels allow to graphically describe general concepts and their relationships [17], providing a clear view of those concepts.

The Design Science Research (DSR) method considering a three cycle view, proposed by [18], is applied to develop the metamodel, which is considered as an artifact within the DSR scope. In the Relevance Cycle, we consider as requirement a set of elements of a smart assessment with their relationships. The research activities of the Design Cycle comprise the design and evaluation of the model in an iterative cycle. The evaluation is based on checking if the structure of the model complies with concepts from our source of knowledge (composed of the scientific literature and the international standards) within the Rigour Cycle without discrepancies.

This paper is organised as follows. Section 2 presents the related work. Section 3 presents the metamodel for Smart Assessment with a description of its elements. Section 4 describes a specialization of the metamodel for Business Process Interoperability. Finally, Section 5 presents the conclusions and future research perspectives. 


\section{Related Work}

The search for a better assessment process has been widely addressed in the scientific literature during the years. Some works have pursued the improvement of the assessment process through the automation of some of its activities and, in certain cases, the entire assessment. The work by [14] describes the SEAL of Quality Assessment Tool, which is a software tool for software process assessment. Its main functionality is based on storing the model framework as records in tables of a database. The paper by [19] presents a knowledge-based decision support system for measuring enterprise performance. It is based on a knowledge base that contains a set of rules that are used for inference over a set of weights or scores given by top managers considering key performance dimensions. In [20], an intelligent maturity model assessment tool was proposed. The system has three main properties: a generic data model enabling the use of different maturity models, it is connected to a BPM system allowing to extract part of the information necessary to perform the assessment, and an assistant function that recommends improvement suggestions based on the problems identified during the assessment. In [12], the authors present the Software-mediated Process Assessment (SMPA) to automate the assessment of IT Service Management processes. The tool allows to select the process to be assessed and the data is collected via an online survey. The results are obtained by automatically analyzing the collected data to measure the process capability. The work by [16] presents the AssessAgility software tool that aims at automating and guiding the assessment process based on an exemplar assessment process containing the definitions and guidance to conduct assessments following AgilityMod [4], which is a reference model for performing agility assessment in organisations. The work by [13] describes the development of a Software as a Service tool for carrying out business process assessment projects using the TIPA framework [21]. The latest version of the software (beta) allows to cover almost all activities of an assessment process, from the definition of the assessment to the results presentation activity.

Approaches that rely on ontologies are frequent for improving the assessment process. An ontology is a representation of explicit formalized knowledge that has as main objective the sharing of a common understanding of specific aspects of certain domain and the relationship between its elements [22]. The approach introduced in [10], for instance, is an ontology-based Records Management (RM) evaluation system. It is based on a reasoner that classifies information in a database, containing the baseline and the actual state of the RM system, as asserted individuals in the ontology, which was devised by a knowledge-engineer. The paper by [23] also proposed a system with an ontology at its core, which is based on the association of sustainable manufacturing with concepts of resources, processes, product, and their functions. The approach by [11] is intended to be an enhancement of the CoSEEEK framework introduced by [24]. It focuses on providing automated software engineering process assessment with the capability to support various process assessment reference models defined by standards such as CMMI [25], ISO/IEC 15504 [26], and ISO 9001 [27]. The work by [15] 
proposed a semi-automated tool for enterprise interoperability assessment that was based on an ontological core in order to automate the Results Calculation phase of an assessment of enterprise interoperability.

A variety of methods discussed in this section are focused on automating single activities, instead of providing means to enhance the entire assessment process through automation methods. Hence, fully automating the assessment process is a research gap addressed by few works. Regarding data collection, there is also a gap related to the tendency to consider only the usage of data originated through asking and deriving strategies (interviews, document reviews, etc.) or data provided by automatic means without considering both paths. Indeed, hybrid data collection approaches are not frequent in the literature. The work by [11] gives a step forward in this direction, since it relies on the use of process mining techniques to automatically extract data from event logs available in information systems [28] and also providing the possibility to manually introduce input data for the assessment. However, the approach is devised specifically for the software process engineering domain. On the other hand, ontologies seem to have emerged as relevant tools for automating the results determination phase of the assessment. Nevertheless, by nature they are highly dependent on human experts that must manually design them. Moreover, depending on the requirements of the application, user-defined rules [29] may also be necessary to provide assessment results. Considering these aspects, a framework to perform assessment in organisations relying on smart capabilities is required to further improve the activities of the assessment process. In this sense, the metamodel introduced in this work is the first step towards the achievement of this objective.

\section{The Smart Assessment Metamodel}

The concept of smartness is a trending term nowadays. Different initiatives such as Smart Cities [30], Smart Manufacturing [31] and Smart Homes [32] have gained strength in both the industry and the scientific community. Smartness as a concept is associated to some characteristics that may enable improvements of the functioning of certain entities. These characteristics include knowledge, selforganisation, perception, actuation and capabilities such as learning, reasoning, and inference. Providing smart characteristics to the assessment process may imply the improvement not only of the result of an assessment but also the diverse activities and sub-activities that are carried during the entire process.

The metamodel for Smart Assessment presented in this work was developed considering the assessment concepts described in the standards ISO 9001 [27], ISO/IEC 33001 [33] and 33002 [34], the Systems Engineering Body of Knowledge [35], and the General System Theory (GST) [36]. On the other hand, considering smart capabilities, we performed a literature review to obtain papers containing definitions of smart entities in order to extract common characteristics. The review was based on a cycle composed of three phases: keywords definition, literature search, and results analysis. Two search strings were defined, both focused on obtaining explicit definitions of smart entities within papers from the 
literature: "\{smartness is $\}$ " and " $\{$ we define smart* $\}$ OR $\left\{\right.$ smart $^{*}$ is defined $\}$ ". The search was performed on databases including ACM, Scopus, IEEE_Xplore, Taylor \& Francis Online, Web of Science, SpringerLink, and Wiley. The obtained papers were filtered considering only those containing explicit definitions and the definitions were manually extracted. Finally, the characteristics were isolated in order to serve as part of the Knowledge Base within the DSR method. A total of 177 definitions were extracted during the literature review, which served to devise the Smart Assessment metamodel in addition to the references mentioned before. The proposed model is shown in Figure 1.

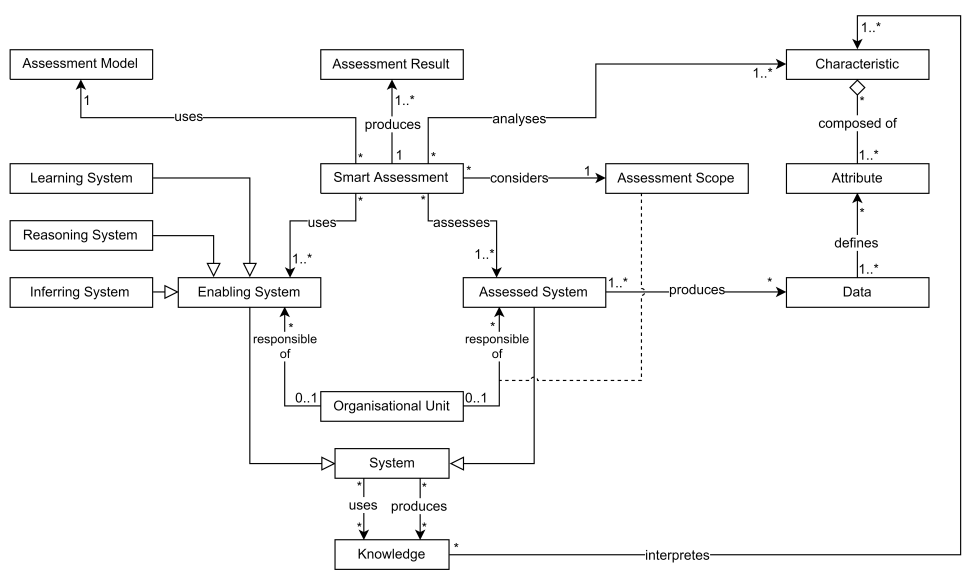

Fig. 1: Conceptual model defining the components of a smart assessment.

The metamodel contains the Smart Assessment element that assesses an Assessed System and uses an Enabling System to properly carry out the main phases of the assessment process, namely, data collection, data validation, results determination, and results presentation. Both elements are sub-types of the element System, which is able to use and produce Knowledge, and both are managed by the organisational Unit element. For the Assessed System, the organisational Unit could be represented by an enterprise or a group of decision-makers responsible for the element. Note that from this relationship a new element emerges: the Assessment Scope, which is mainly focused on defining the boundaries of the assessment established by the organisational Unit. The emergence relationship is marked with a dotted line in the metamodel. On the other hand, the Enabling System element is also managed by the organisational Unit element that is responsible for employing and organising it in order to perform the assessment. An Enabling System is responsible to support a System-of-Interest [35], which is the system of interest of an observer [36]. In our metamodel, the System-of-Interest is the Assessed System. Note that in order to have a Smart Assessment, elements such as Learning System, Reasoning System, or Inferring System must be present. The former is capable of producing 
Knowledge, whilst the others are focused on using it. These elements, along with properties such as perception (sensors) and control (actuators), provide smart capabilities to the assessment process. Note that sensor and actuator elements are not included in the metamodel due to their low abstraction level, however they must be considered at the time of implementation.

The Smart Assessment uses the Assessment Model element, which is a conceptual framework describing the architecture of a system and the way its elements interact [37]. The Smart Assessment also produces Assessment Results. The Assessed System produces Data, which are representative of the Attributes of the system, hence the relationship in the metamodel. On the other hand, the Characteristic of the Assessed System is, in fact, a group of its Attributes. Note that these three elements can be seen as organised components of the Wisdom Hierarchy [38], which is composed of Data, Information, Knowledge and Wisdom. The Data element of the metamodel is in the Data level of the hierarchy, the Attribute element is in the Information layer, whilst the Characteristic element can be considered as part of the Knowledge level of the hierarchy, which is pointed through its relation with the Knowledge element in the metamodel. In fact, the Knowledge element may serve as an interpretation of the Characteristic of the Assessed System to be analysed, and it serves as basis for the decision making regarding the final Assessment Result. Moreover, we consider the Assessment Result element to be at the Wisdom level of the Wisdom Hierarchy, since it ultimately aims at providing the capacity to make optimal decisions regarding the Assessed System based on the existing knowledge about that element [39].

\section{Towards a Business Process Interoperability Smart Assessment}

organisations face challenges and pressures on a daily basis. These challenges include competitiveness, cost reduction, customer satisfaction, innovation, or product quality. Among these issues, organisations also have the necessity to interoperate in order to share information and achieve objectives [40]. Interoperability is the ability of enterprises to interact, and research in the field is mostly based on removing interoperability barriers [41]. It can occur between the following organisational layers: data, services, processes and businesses [41]. Considering the process layer, interoperability pursuits to make various organisational processes collaboratively work in a standardised manner [41]. Moreover, the literature presents three ways to relate systems in order to interoperate: integrated approach (a common format is defined for models), unified approach (a common format exists but at the meta-level only), and federated approach (there is no common format for models) [42].

In this context, we present a specialization of the metamodel described in Section 3 aiming at exploring its capability to adapt to more specific needs. The specialized model is focused on Business Process Interoperability Smart Assessment. Hence, the process organisational layer described before is considered for the instantiation. The new elements introduced for the specialized metamodel 
are defined specifically in the Ontology of Enterprise Interoperability (OoEI) [43], the Maturity Model for Enterprise Interoperability (MMEI) [3], and the standard ISO/IEC 33001 [33] for process assessment concepts and terminology.

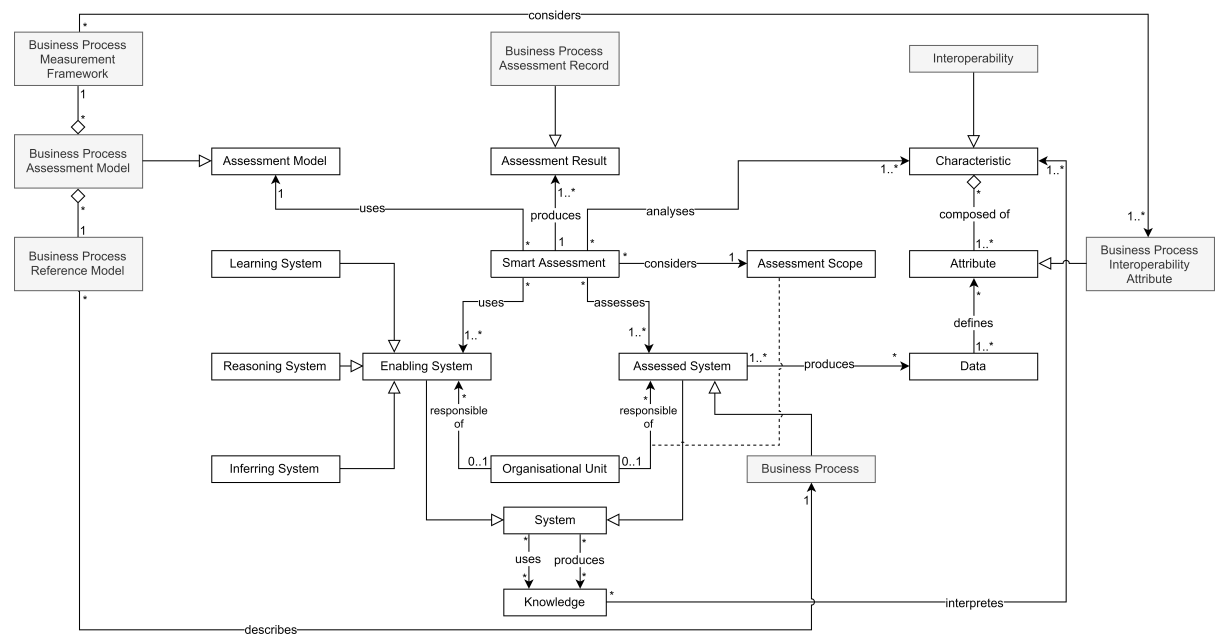

Fig. 2: Smart assessment instantiated for process capability.

The specialization includes Business Process as a type of Assessed System. It also includes a Business Process Assessment Model, which is composed of a Business Process Reference Model and a Business Process Measurement Framework. The latter is a schema used to characterize a certain Characteristic element, specialized for Interoperability in the metamodel. The attributes considered for the assessment are Business Process Interoperability Attributes. Finally, the Business Process Assessment Record is a sub-type of Assessment Result that provides results in terms of which interoperability barriers the assessed business process is facing and the possible means to remove those barriers through recommended best practices.

\section{Conclusion}

This work presented a metamodel describing the Smart Assessment concept with its elements and their relationships through a visual diagram. The Design Science Research methodology was applied to develop the metamodel, which is intended to serve as initial artifact in the pursuit of a framework for Smart Assessment able to provide means to enhance the assessment process of systems. The artifact is devised to evolve following an iterative approach by considering the feedback received from the community and experiments consisting of the implementation of instances of the elements defined in the metamodel in real-world scenarios. 
The proposed metamodel was specialized for Business Process Interoperability Smart Assessment. For this purpose, we relied on literature and standard documents addressing process and interoperability assessment. This specialization allowed to experiment with the generalization capability of the model, and we consider that it provides the proper structure to be specialized for different domains and assessment approaches. Moreover, we consider that the model is not applicable only for organisational assessment but also to a diverse range of contexts.

We expect that this work will serve as a contribution to the development of smarter assessment methods, tools, and artifacts, independently from particularities derived from the assessed system for which the appraisal approach is devised for and the assessment models used to perform it. Future work will aim at refining the artifact by analysing the feedback obtained from the experience of modelling specialized Smart Assessments considering different scenarios. The metamodel will also serve as cornerstone of the development specific implementations devised for real-world situations that will be evaluated through case studies. Indeed, this is a natural step forward for the research introduced in this paper, which will be followed by the authors.

\section{References}

1. Van Looy, A., Shafagatova, A.: Business process performance measurement: a structured literature review of indicators, measures and metrics. SpringerPlus 5(1), 1797 (Oct 2016). https://doi.org/10.1186/s40064-016-3498-1, https://doi.org/10.1186/s40064-016-3498-1

2. Looy, A.V., Backer, M.D., Poels, G.: Defining business process maturity. a journey towards excellence. Total Quality Management \& Business Excellence 22(11), 1119-1137 (2011). https://doi.org/10.1080/14783363.2011.624779, https://doi.org/10.1080/14783363.2011.624779

3. Guédria, W., Naudet, Y., Chen, D.: Maturity model for enterprise interoperability. Enterprise Information Systems 9(1), 1-28 (2015). https://doi.org/10.1080/17517575.2013.805246, https://doi.org/10.1080/17517575.2013.805246

4. Ozcan-Top, O., Demirörs, O.: A reference model for software agility assessment: Agilitymod. In: International Conference on Software Process Improvement and Capability Determination. pp. 145-158. Springer (2015)

5. Schumacher, A., Erol, S., Sihn, W.: A maturity model for assessing industry 4.0 readiness and maturity of manufacturing enterprises. Procedia Cirp 52, 161-166 (2016)

6. Oliva, F.L.: A maturity model for enterprise risk management. International Journal of Production Economics 173, 66-79 (2016)

7. Yahia, E., Aubry, A., Panetto, H.: Formal measures for semantic interoperability assessment in cooperative enterprise information systems. Computers in Industry 63(5), 443-457 (2012)

8. De Bruin, T., Freeze, R., Kaulkarni, U., Rosemann, M.: Understanding the main phases of developing a maturity assessment model. ACIS 2005 Proceedings (2005)

9. Proença, D., Borbinha, J.: Maturity models for information systems-a state of the art. Procedia Computer Science 100, 1042-1049 (2016) 
10. Alalwan, Thomas: An Ontology-based Approach to Assessing Records Management Systems. e-Service Journal 8(3), 24 (2013). https://doi.org/10.2979/eservicej.8.3.24

11. Grambow, G., Oberhauser, R., Reichert, M.: Automated Software Engineering Process Assessment: Supporting Diverse Models using an Ontology. Int'l Journal on Advances in Software 6(1 \& 2), 213-224 (2013)

12. Cater-Steel, A., Valverde, R., Shrestha, A., Toleman, M.: Decision support systems for IT service management. International Journal of Information and Decision Sciences 8(3), 284 (2016). https://doi.org/10.1504/ijids.2016.078588

13. Barafort, B., Shrestha, A., Cortina, S., Renault, A.: A software artefact to support standard-based process assessment: Evolution of the tipa $\mathbb{R}$ framework in a design science research project. Computer Standards \& Interfaces 60, 37-47 (2018)

14. Lok, R.H., Walker, A.J.: Automated tool support for an emerging international software process assessment standard. In: Proceedings of IEEE International Symposium on Software Engineering Standards. pp. 25-35 (June 1997). https://doi.org/10.1109/SESS.1997.595563

15. Leal, G.S., Guédria, W., Panetto, H., Proper, E.: Towards a semi-automated tool for interoperability assessment: An ontology-based approach. In: International Conference on Software Process Improvement and Capability Determination. pp. 241-254. Springer (2017)

16. Adali, O.E., Top, O.O., Demirors, O.: Assessment of agility in software organizations with a web-based agility assessment tool. Proceedings - 43rd Euromicro Conference on Software Engineering and Advanced Applications, SEAA 2017 pp. 88-95 (2017). https://doi.org/10.1109/SEAA.2017.61

17. Gascueña, J.M., Navarro, E., Fernández-Caballero, A.: Model-driven engineering techniques for the development of multi-agent systems. Engineering Applications of Artificial Intelligence 25(1), 159-173 (2012)

18. Hevner, A.R.: A three cycle view of design science research. Scandinavian journal of information systems 19(2), 4 (2007)

19. Wen, W., Chen, Y.H., Chen, I.C.: A knowledge-based decision support system for measuring enterprise performance. Knowledge-Based Systems 21(2), 148-163 (2008). https://doi.org/10.1016/j.knosys.2007.05.009

20. Krivograd, N., Fettke, P., Loos, P.: Development of an intelligent maturity model-tool for business process management. Proceedings of the Annual Hawaii International Conference on System Sciences pp. 3878-3887 (2014). https://doi.org/10.1109/HICSS.2014.481

21. Barafort, B., Rousseau, A., Dubois, E.: How to design an innovative framework for process improvement? the tipa for itil case. In: European Conference on Software Process Improvement. pp. 48-59. Springer (2014)

22. Gruber, T.R.: A translation approach to portable ontology specifications. Knowledge acquisition 5(2), 199-220 (1993)

23. Giovannini, A., Aubry, A., Panetto, H., Dassisti, M., El Haouzi, H.: Ontologybased system for supporting manufacturing sustainability. Annual Reviews in Control 36(2), 309-317 (2012). https://doi.org/10.1016/j.arcontrol.2012.09.012, http://dx.doi.org/10.1016/j.arcontrol.2012.09.012

24. Oberhauser, R.: Leveraging semantic web computing for context-aware software engineering environments. In: Semantic Web. IntechOpen (2010)

25. Team, C.P.: Cmmi for development, version 1.3. Tech. Rep. CMU/SEI-2010-TR033, Software Engineering Institute, Carnegie Mellon University, Pittsburgh, PA (2010), http://resources.sei.cmu.edu/library/asset-view.cfm?AssetID=9661 
26. Secretary, I.C.: Iso/iec 15504-2: Information technology - process assessment - part 2: Performing an assessment. Standard, International Organization for Standardization (2004)

27. ISO Central Secretary: ISO 9001: Quality management systems - Requirements. Standard, International Organization for Standardization, Geneva, CH (Sep 2015)

28. Van Der Aalst, W.: Process mining: discovery, conformance and enhancement of business processes, vol. 2. Springer (2011)

29. Wang, X., Zhang, D., Gu, T., Pung, H.K., et al.: Ontology based context modeling and reasoning using owl. In: Percom workshops. vol. 18, p. 22. Citeseer (2004)

30. Koutra, S., Becue, V., Ioakimidis, C.S.: Searching for the 'smart' definition through its spatial approach. Energy 169, $924 \quad-936$ (2019). $\quad$ https://doi.org/https://doi.org/10.1016/j.energy.2018.12.019, http://www.sciencedirect.com/science/article/pii/S0360544218323855

31. Kang, H.S., Lee, J.Y., Choi, S., Kim, H., Park, J.H., Son, J.Y., Kim, B.H., Do Noh, S.: Smart manufacturing: Past research, present findings, and future directions. International Journal of Precision Engineering and Manufacturing-Green Technology 3(1), 111-128 (2016)

32. Alaa, M., Zaidan, A., Zaidan, B., Talal, M., Kiah, M.L.M.: A review of smart home applications based on internet of things. Journal of Network and Computer Applications 97, 48-65 (2017)

33. Secretary, I.C.: Iso33001: Information technology — process assessment - concepts and terminology. Standard, International Organization for Standardization, Geneva, CH (Mar 2015)

34. ISO Central Secretary: ISO33002: Information technology — Process assessment - Requirements for performing process assessment. Standard, International Organization for Standardization, Geneva, CH (Mar 2015)

35. Board, B.E.: The guide to the systems engineering body of knowledge (sebok) (2017)

36. Von Bertalanffy, L.: General system theory. New York 41973(1968), 40 (1968)

37. B., V., Leon, J.: Evaluating the quality of reference models. In: Laender, A.H.F., Liddle, S.W., Storey, V.C. (eds.) Conceptual Modeling — ER 2000. pp. 484-498. Springer Berlin Heidelberg, Berlin, Heidelberg (2000)

38. Rowley, J.: The wisdom hierarchy: representations of the dikw hierarchy. Journal of information science 33(2), 163-180 (2007)

39. Rowley, J.: Where is the wisdom that we have lost in knowledge? Journal of Documentation 62(2), 251-270 (2006)

40. Leal, G.d.S.S., Guédria, W., Panetto, H.: Interoperability assessment: A systematic literature review. Computers in Industry 106, 111-132 (2019)

41. Chen, D.: Enterprise interoperability framework. In: EMOI-INTEROP (2006)

42. ISO Central Secretary: ISO 14258: Industrial automation systems - Concepts and rules for enterprise models. Standard, International Organization for Standardization, Geneva, CH (Mar 1998)

43. Naudet, Y., Latour, T., Guedria, W., Chen, D.: Towards a systemic formalisation of interoperability. Computers in Industry 61(2), 176 185 (2010). https://doi.org/https://doi.org/10.1016/j.compind.2009.10.014, http://www.sciencedirect.com/science/article/pii/S0166361509002073, integration and Information in Networked Enterprises 